\title{
The Effectiveness of Portage Early Intervention Program in Improving Adaptive Behavior Skills with Intellectual Disorders
}

\author{
Ashraf Bader Alddin Al-Wedyan ${ }^{1} \&$ Alia Mohammed Al-Oweidi ${ }^{2}$ \\ ${ }^{1}$ Al al_Bayt University, Amman, Jordan \\ ${ }^{2}$ Faculty of Education, The World Islamic Sciences \& Education University, Amman, Jordan \\ Correspondence: Alia Mohammed Al-Oweidi, Faculty of Education, The World Islamic Sciences \& Education \\ University, Amman, Jordan.
}

Received: August 3, 2021

doi:10.5539/ies.v15n1p16
Accepted: September 26, 2021

Online Published: December 23, 2021

URL: https://doi.org/10.5539/ies.v15n1p16

\begin{abstract}
The aim of this study was to find the effectiveness of the Portage Program for Early Intervention in improving cognitive competencies of mothers with children having intellectual disabilities in applying portage program, and in developing those children's adaptive behavior. The experimental sample included 10 children from Irbid Governorate with simple intellectual disabilities, using single-group experimentation. To achieve the goal of the study, the Portage Program (second edition) was adopted as well as the cognitive competence scale for pre and post-test, and the adaptive behavior scale for children with intellectual disabilities. Data from the implemented scales were treated statistically using proper statistical methods. The study reached the following results: There were statistically significant differences at the level of significance $(\alpha=0.05)$ between the means of the pre- and post-test for performance of mothers of children with simple intellectual disabilities in the cognitive competence scale. There were statistically significant differences at the level of significance $(\alpha=0.05)$ between the pre- and post-test means for performance of children with simple intellectual disabilities in the adaptive behavior scale. There were statistically significant differences at the level of significance $(\alpha=0.05)$ between the post and follow up test means for performance of children with simple intellectual disabilities in the adaptive behavior scale. The study sets various recommendations in the fields of education and research. The results of the qualitative analysis indicated a noticeable improvement in the performance of the adaptive behavior skills of the individuals participated in study.
\end{abstract}

Keywords: portage program, mothers with children having intellectual disabilities, adaptive behavior

\section{Introduction}

Disability is considered a great burden on the disabled person and his family, as it greatly limits his potential and constitutes a major obstacle to his participation in society and the usual practice of his life, and the family has a responsibility to help the child adapt and depend on himself as much as possible, and the mother bears the greatest responsibility, especially in providing the child with behavioral skills (Hamdan, 2013).

Adaptive behavior skills are among the most important skills that the mentally disabled need in their daily lives. They are considered essential for the disabled in general to engage in society and interact with his surrounding environment, and a basic condition for the integration of individuals with special needs in schools and society (Al Rousan, 2018).

Early intervention includes providing various medical, social, educational and psychological services to children with disabilities under the age of six, and focuses on developing the skills and abilities of parents to help their children grow, learn and meet their needs as parents and the complex and multiple needs of their children through a multidisciplinary team to deal with children with Intellectual disability and their families. (Biber \& Ural, 2016).

The association of family education with preschool education is more effective, as the child receives education with his parents at home, and from here emerged the philosophy of the Portage Early Education program, as it is an early educational program prepared to give support to children from 0 to 6 years of age with normal development (Biber \& Ural, 2016).

The Portage program originated in 1969 in the state of Wisconsin in the United States of America, and it is one of the few projects recommended for children with special needs in the preschool period, in order to qualify them to 
move from home to school. The main objective of Portage programs was to serve children in remote places, and one of the most important features of it is that its educational procedures and systems consider the family an essential partner in the decision-making process related to the type and nature of services and accompanying activities (Herwig \& Herman, 1993).

Due to the importance of adaptive behavior in the life of a mentally disabled child, and the presence of obstacles and difficulties facing the family of children with intellectual disabilities, all of this was the motive to conduct a study aimed at identifying the effectiveness of the Portage program (second edition) targeting mothers to raise and improve their competencies in dealing with their children in order to enhance their acquisition of adaptive behavior skills.

Intellectual disability: Intellectual disability is considered one of the categories of special education, and it has been defined by many specialists in the subject of disabilities. Here are some of these definitions:

A developmental disorder that results in impairment of mental and adaptive functions in the cognitive and socio-practical areas.

There is a set of criteria that must be met to consider a person with an intellectual disability:

Deficiencies in mental functions such as reasoning, problem solving, planning, abstract thinking, judgment, academic learning and learning from experiences.

Deficiencies in adaptive functioning that leads to failure to meet the developmental and cultural standards necessary for personal independence and social responsibility.

Occupational and adjustment deficits during the growth period (American Psychiatric Association (APA), 2013).

The American Association on Intellectual and Developmental Disabilities (AAIDD) defined intellectual disability as a clear deficiency represented by mental and functional deficiencies expressed by the degree of intelligence that deviates two standard deviations below the mean, and deficiencies in adaptive behavior expressed in deficiencies in social-conceptual skills and adaptive skills that appear before the age of 18 years (Hallahan, Kaufman, \& Pollan, 2013).

Adaptive behavior: The concept of adaptive behavior appeared in the field of special education with the emergence of social definitions of intellectual disability, which define an individual with intellectual disability based on his ability to achieve the social requirements expected of him compared to his peers in his chronological age, and the concept aims to increase the accuracy of evaluation and diagnosis, in order to contribute to decision-making on the extent of individuals' need for special education services, in an effort to help the individual with intellectual disability achieve independence to the maximum possible degree (Duffy, 2007).

The individual's failure to perform the adaptive behavior skills expected of him, and the deficiency in achieving personal independence, are among the indicators that infer the existence of a defect or deficit in the individual's abilities (Ditterline \& Oakland, 2009).

The following are the most prominent areas of adaptive behavior in which the characteristics of individuals with intellectual disabilities appear

Language and communication skills: where the deficiency appears in communication skills, as they repeat the words they hear, and thus this affects their communication with others (Janzen, 2003).

Areas of interaction and relationships: This is evident in their interaction with others, as they avoid eye contact, and tend to play individually away from the participation of others in addition to their attachment to strange things that have no value (Al Rousan, 2018).

Portage Program: It is an early learning program applied to children with disabilities who suffer from developmental delay or at risk from birth to under the age of three in their places of residence, and from the age of three until under the age of six in early learning centers or at home.

The program aims to train families and caregivers to deal with children. It also prepares all enrolled children to learn in the least restrictive and most appropriate environments for them. The program serves all children in addition to children with developmental delay and those at risk.

Al shammari (2014) conducted a study aimed at exploring the effect of motor activities in the Portage Early Intervention Program on the development of motor skills and self-concept among children with Down syndrome in kindergartens in the State of Kuwait, where the study sample consisted of 20 children with Down syndrome who suffer from deficiencies in motor skills and self-concept. In order to achieve the objectives of the study, they were divided equally into two groups: The first was an experimental one that was trained on motor skills by the Portage 
program, The second was a control who was not trained on anything, and the results showed that there were statistically significant differences between the mean scores of the experimental and control groups in the post application of the motor skills scale in favor of the experimental group.

Ibrahim (2015) also conducted a study aimed at demonstrating the effectiveness of the Portage program to develop some technical and innovative skills for kindergarten children (4-6) years old, who were chosen randomly from the first and second levels of kindergarten at Taif International School. To achieve the objectives of the study, a scale was used for some innovative technical skills to be applied as a pre and post-test on the child, as well as the Portage program. The results indicated that there were statistically significant differences in the technical and innovative skills scale after applying the program in favor of the experimental program, as well as the effectiveness of the program based on some Portage activities.

Al-Bdour (2017) conducted a study aimed at finding out the effectiveness of a training program for parents based on behavioral theory in improving their cognitive competencies and measuring its impact on modifying the behavior of their children with autism in Jordan. The study sample consisted of (60) parents of children with autism spectrum, as they were randomly distributed to two control and experimental groups, and the results indicated that there were statistically significant differences in favor of the experimental group, which means that the training program contributed to the development of their cognitive competencies.

Qasim (2017) conducted a study aimed at finding out the effectiveness of a training program for early intervention, using the Portage program for a sample of graduate students at the Department of Psychological Counseling at the University of Sohag - Republic of Egypt, in preparing the home teacher for the comprehensive development of early childhood. The sample consisted of (20) students, who underwent training on the Portage program, where (12) students were selected for the purposes of applying the Portage program to a sample of children and their mothers. The number of families that were worked with was (24 mothers and their children). In order to achieve the objectives of the study, a training program for preparing a home teacher, a Portage program for early intervention, evaluation tools for the Portage program, and a form for mothers 'evaluation of the competency of domestic teachers were used. The results indicated the efficiency of the home teachers trained in using Portage in improving the development of children, as well as the efficiency of the home teachers in using Portage from the mothers' point of view.

Heiba (2017) conducted a study aimed at identifying the effectiveness of the Portage program in improving the psycho-linguistic development of a sample of mentally disabled children aged between (4-6) years who are able to learn in the Republic of Egypt. Where the study used the quasi-experimental approach, and the sample was (20) children, who were distributed into two equal groups (10 for the experimental group and 10 for the control group), and the results indicated the effectiveness of the program in improving the psycho-linguistic development of mentally disabled children who are able to learn.

Artero Prado et al. (2012) conducted a study aimed at assessing the growth and development of children in kindergarten, and the intervention for those with movement delay, in Brazil, where the sample consisted of 15 children ( 8 males, 7 females) between newborns and up to the age of two years. The results indicated that early intervention was effective in the motor development of children.

Biber and Ural (2016) conducted a study aimed at investigating the impact of the Portage program for early intervention on family participation and the development of children in the age group (4-6) years who are enrolled in kindergarten, in the city of Balikesir, where the sample consisted of 64 children. The pre and posttest was applied to the study sample, and the results indicated that the Portage program had an impact on both children and families.

Pianezzola de Oliveira et al. (2018) conducted a study aimed at investigating the effect of early intervention on movement and cognition in children with Down syndrome in Brazil, where the sample consisted of a group of children aged 0-1 years in an integration center who were not subjected to any of the other early intervention programs, where a comparison of the child's performance with himself before and after the intervention was shown on a behavioral growth measurement tool of the child's behavior, and the results indicated an improvement in children's performance by more than $50 \%$ compared to the initial evaluation.

\subsection{Study Problem}

The family of a child with an intellectual disability, and the mother in particular, suffer from many conditions and factors that hinder the training of the child to adapt to his disability, as mothers in general suffer from deficiencies in the skills necessary to deal with their children with intellectual disability, and some families suffer from low economic level, in addition to the low absorptive capacity in government centers, and some families may suffer 
from difficulties in moving from home to the center, and this daily suffering experienced by the family of a mentally disabled child is considered necessary and important needs so that this family can provide service to its child, This is confirmed by the study of Abd Alaziz (2012), which aimed to identify the cognitive, material, psychological, and social needs of families of children with intellectual disabilities.

Many studies have emphasized the importance of early stages in a child's learning, such as the study of Al-Qudah (2010), which emphasized the importance of early intervention programs in developing daily life skills for a group of children with Down syndrome.

Adaptive behavior is also related to the development of the child, as the manifestations of adaptive behavior are skills that grow and increase with age. And the culture to which the individual belongs and the social expectations imposed by a situation, play a fundamental role in the formation of these skills, in addition to the ability of the individual to meet and perform adaptive behavior skills that plays an important role towards achieving personal independence, and his failure to meet adaptive behavior skills is a strong indication that there is something wrong with this child (Duffy, 2007).

Therefore, the need arose for the importance of establishing a training program targeting mothers at home, and studying its effectiveness in raising mothers' cognitive competencies in dealing with their children.

\subsection{Study Questions}

The research problem lies in answering the following main question:

- What is the effectiveness of the Portage Early Intervention Program in improving the cognitive competencies of mothers of children with intellectual disabilities and developing the adaptive behavior skills of their children?

- Are there statistically significant differences at the level of significance $(\alpha=0.05)$ between the arithmetic means of the pre and post-tests of the performance of mothers of children with simple intellectual disabilities on the Cognitive Competency Scale??

- Are there statistically significant differences at the level of significance $(\alpha=0.05)$ between the arithmetic means of the pre and post-tests of the performance of children with simple intellectual disability on the Adaptive Behavior Scale?

- Are there statistically significant differences at the level of significance $(\alpha=0.05)$ between the arithmetic means of the post and follow up tests of the performance of children with intellectual disabilities on the Adaptive Behavior Scale?

\section{Method}

\subsection{Study Methodology}

The one-group, pre-experimental approach was used with two measures (pre-experimental and posttest design). This is due to its relevance to the objectives of this study.

\subsection{Study Population}

10 children with simple intellectual disability were selected intentionally, and their ages ranged between (3-9) years and did not suffer from other disabilities. Their ten mothers were not specialized in special education or psychological sciences and did not undergo any kind of home training to deal with their children, and they have shown willingness to participate in the study procedures. They also receive service in a special education center.

Table 1 shows the characteristics of the study sample. 
Table 1. Characteristics of the study sample of mothers and their children with simple intellectual disability

\begin{tabular}{|c|c|c|c|c|c|c|c|}
\hline No. & Age & Gender & $\begin{array}{c}\text { Degree and type } \\
\text { of disability }\end{array}$ & $\begin{array}{l}\text { Child rank in the } \\
\text { family }\end{array}$ & $\begin{array}{c}\text { Family income } \\
\text { level }\end{array}$ & $\begin{array}{c}\text { The educational level of } \\
\text { the mother }\end{array}$ & $\begin{array}{l}\text { Mother's } \\
\text { current age }\end{array}$ \\
\hline 1 & 4 years & $\mathrm{F}$ & $\begin{array}{c}\text { Simple } \\
\text { intellectual }\end{array}$ & Last one & Good & High school & 49 \\
\hline 2 & 3 years & $\mathrm{F}$ & $\begin{array}{c}\text { Simple } \\
\text { intellectual }\end{array}$ & Last one & Good & BA & 46 \\
\hline 3 & 3 years & $\mathrm{F}$ & $\begin{array}{c}\text { Simple } \\
\text { intellectual }\end{array}$ & Last one & Moderate & Diploma & 50 \\
\hline 4 & 5 years & M & $\begin{array}{c}\text { Simple } \\
\text { intellectual }\end{array}$ & Last one & Moderate & Preparatory & 47 \\
\hline 5 & 5 years & M & $\begin{array}{c}\text { Simple } \\
\text { intellectual }\end{array}$ & Last one & Moderate & High school & 47 \\
\hline 6 & 9 years & M & $\begin{array}{c}\text { Simple } \\
\text { intellectual }\end{array}$ & Last one & Good & $10^{\text {th }}$ grade & 43 \\
\hline 7 & 9 years & $\mathrm{F}$ & $\begin{array}{c}\text { Simple } \\
\text { intellectual }\end{array}$ & Last one & Good & High school & 51 \\
\hline 8 & 3 years & $\mathrm{F}$ & $\begin{array}{c}\text { Simple } \\
\text { intellectual }\end{array}$ & Last one & Moderate & BA & 44 \\
\hline 9 & 5 years & M & $\begin{array}{c}\text { Simple } \\
\text { intellectual }\end{array}$ & $4^{\text {th }}$ one & Moderate & BA & 40 \\
\hline 10 & 7 years & $\mathrm{F}$ & $\begin{array}{c}\text { Simple } \\
\text { intellectual }\end{array}$ & $1^{\text {st }}$ one & Low & Diploma & 29 \\
\hline
\end{tabular}

We note from the above table that all children are ranked last in the family except for the ninth child, as the tenth child is also considered the last because his mother has not given birth after him, and it is also noted that the reproductive age of most mothers is over forty.

\subsection{Study Tools}

To achieve the objectives of the study, the study included two tools:

First: Cognitive Competency Scale among mothers of children with intellectual disabilities

The scale aims to reveal the level of cognitive competencies among mothers of children with intellectual disabilities. This will, in the event of being able to improve their cognitive competencies, be reflected in their ability to develop adaptive behavior skills in their children with simple intellectual disabilities. Therefore, the scale items were derived from the Portage program in its second version (Tabbal, 2014).

Indications of validity and reliability of the cognitive competency scale of mothers of children with intellectual disabilities:

\section{1) Content validity}

The validity of the content was verified for the items of the Cognitive Competency Scale of Mothers of Children with Intellectual Disabilities. By presenting it to a group of arbitrators specialized in the field of special education, with the aim of expressing their views on the accuracy and validity of the content of the scale.

\section{2) Construct validity}

To verify the validity of the construction of the items of the cognitive competency scale of mothers of children with intellectual disabilities; the scale was applied to an exploratory sample of twenty mothers of children with simple intellectual disability at the Fina Al-Khair Center and Al-Aoun Center for Special Education from outside the study sample, Where the correlation coefficients were calculated for the relationship of the items of the cognitive competency scale with the scale, as shown in Table 2. 
Table 2. The values of the corrected correlation coefficients for the relationship of the cognitive competency scale items to the scale

\begin{tabular}{clc}
\hline Item & The items of mothers' cognitive competency scale & Item Corrected Correlation with Scale* \\
\hline 1 & I can fill out the information form for my son according to the Portage program & 0.87 \\
2 & I have knowledge of the mechanism for applying the check-list on the skill to be & 0.64 \\
3 & measured & I have knowledge of the appropriate age group for my son to start applying the checklist \\
4 & I can estimate the time needed to perform the skill & 0.84 \\
5 & I have the knowledge of the necessary tools for each of the test items & 0.41 \\
6 & I can do the skill in front of my son & 0.46 \\
7 & I Train my son on the skill, going from easiest to hardest & 0.43 \\
8 & I determine the chronological age of my son based on the Portage program & 0.43 \\
9 & I set my son's baseline based on the Portage program & 0.84 \\
10 & I define my son's education area based on the Portage program & 0.86 \\
11 & I help suggest activities needed to design a family based plan & 0.95 \\
12 & I can determine my son's strength & 0.87 \\
13 & I can determine my son's weakness & 0.79 \\
14 & I can use the daily routine to educate my son & 0.49 \\
15 & I can implement the family based plan with every skill & 0.54 \\
16 & I evaluate my son's performance on the skill I trained him in & 0.44 \\
17 & I set the the maximum line for my son based on Portage program & 0.48 \\
18 & I reward my son when performing the required skill & 0.68 \\
19 & I take into account the level of difficulty in performing the skill that I trained my son to & 0.69
\end{tabular}

* Statistically significant at the level of significance $(\alpha=0.05)$.

Table 2 illustrates that the values of the correlation coefficients for the cognitive competencies items with their scale ranged between (0.41-1.00) and are considered acceptable correlation coefficients in this study.

3) The stability of the cognitive competency scale among mothers of children with intellectual disabilities

The cognitive competency scale was applied to an exploratory sample consisting of twenty mothers of children with simple intellectual disability at the Fina Al-Khair Center and Al-Aoun Center for Special Education from outside the study sample using the Test-Retest method with an interval of two weeks between the two applications. Whereas, the coefficient of stability of the internal consistency of the scale was calculated using the Coder-Richardson 20 equation (KR-20). Its value was (0.82), and the stability coefficients for the scale were calculated two weeks after the application of the first, using the Pearson correlation coefficient between the first and second applications. Its value reached (0.88).

4) Correcting the cognitive competency scale among mothers of children with intellectual disabilities

The cognitive competency scale for mothers of children with simple intellectual disability included (19) items in its final form, answered by two point Likert Scale, the alternatives include: ((No) has a zero degree, (yes) has one degree).

Second: Adaptive Behavior Scale for Children with Intellectual Disabilities.

The scale aims to reveal the level of adaptive behavior skills among children with simple intellectual disabilities. The items were constructed with reference to the Portage program in its second version (Tabbal, 2014; Al Rousan, 2018; Al-Ali, 2010), the Harrison and Oakland scale (Harrison \& Oakland, 2003) and the Vineland Adaptive Behavior Scale (Al-Otaibi, 2004) for age-relevant adaptive behavior of the study subjects.

A. Indications of the validity and reliability of the Adaptive Behavior Scale in Children with Intellectual Disabilities

\section{Content Validity}

The validity of the content was verified for the items of the Adaptive Behavior Scale in Children with Intellectual Disabilities, by presenting it to ten arbitrators specializing in the field of special education in several universities.

B. The evaluators' consistency of the performance of children with simple intellectual disability on the Adaptive Behavior Scale 
To check evaluators' consistency of the performance of children with simple intellectual disability on the Adaptive Behavior Scale: the performance of an exploratory sample consisting of ten children with simple intellectual disability was evaluated on the Adaptive Behavior Scale in both Al Aoun and Fina Al-Khair centers, outside the targeted study sample. As the percentage of agreement was calculated for the self- assessment using the Holste equation for the two assessments made by the researcher with a difference of one month between them, and the agreement percentage was calculated for the inter- assessment using the Holste equation for the two assessments that were conducted by the researcher and by two specialists in each of Al Aoun and Fina Al-Khair centers, as shown in Table 3.

Table 3. The values of agreement percentages for the self-assessment of the researcher and for the two inter-assessments of the researcher with the two specialists for the performance of the children of the survey sample with simple intellectual disability on the scale of adaptive behavior

\begin{tabular}{|c|c|c|c|c|}
\hline \multirow{3}{*}{ Dimension } & \multirow{3}{*}{ Adaptive behavior among children with intellectual disabilities } & \multicolumn{3}{|c|}{ agreement percentage } \\
\hline & & \multirow{2}{*}{ self-evaluation } & \multicolumn{2}{|c|}{ Inter-assessment of the specialist } \\
\hline & & & $1 \mathrm{st}$ & 2nd \\
\hline 1 & Communication & 84.32 & 87.32 & 86.32 \\
\hline 2 & Daily life skills & 90.94 & 93.66 & 92.75 \\
\hline 3 & Socialization & 85.66 & 88.44 & 87.51 \\
\hline 4 & Motor skills & 90.00 & 92.70 & 91.80 \\
\hline \multicolumn{2}{|r|}{ Total scale } & 87.88 & 90.67 & 89.74 \\
\hline
\end{tabular}

Table 3 illustrates: The percentage of agreement for the self- assessment concerned with the researcher's ability to objectively evaluate the performance of children with simple intellectual disability on the adaptive behavior scale was $(87.88 \%)$. The values of agreement ratios for the self-assessment concerned with the researcher's ability to evaluate the performance of children with simple intellectual disability on the dimensions of the adaptive behavior scale ranged between $(84.32 \%-90.94 \%)$. It is noted that the percentage of agreement between the researcher's inter-assessment and the first specialist was $(90.67 \%)$. The values of agreement ratios for the inter-assessment of the researcher with the first specialist on the dimensions of the adaptive behavior scale ranged between $(87.32 \%$ $-93.66 \%)$. It is also noticed that the percentage of agreement between the researcher's inter- assessment and the second specialist was $(89.74 \%$ ), and the agreement ratios for the inter-assessment of the researcher with the first specialist on the dimensions of the second behavior scale were between (86.32\%-92.75\%).

\section{Construct validity}

To verify the construct validity of the items of the "Adaptive Behavior Scale" for children with Intellectual Disabilities, the scale was applied to an exploratory sample of ten children with simple intellectual disability in Fina Al-Khair Center and Al-Aoun Center for Special Education from outside the targeted study sample, where the arithmetic mean was calculated for the evaluations of the researcher and the two specialists for the performance of the children of the survey sample with simple intellectual disabilities on the items of the adaptive behavior scale. With the aim of calculating the corrected correlation coefficients for the relationship of the items of the adaptive behavior scale with the scale and its dimensions, the results indicated that the values of the corrected correlation coefficients for the items of the communication dimension ranged between (0.39-0.99), which are acceptable correlation coefficients for the purposes of the study, and on the scale ranged between (0.31-0.93), and that the values of the corrected correlation coefficients for the items of the "daily life skills" dimension in their dimension ranged between $(0.38-0.38)$ and on the scale ranged between $(0.32-0.85)$, and that the values of the corrected correlation coefficients for items of the" socialization" dimension with their dimension ranged between (0.33-0.85) and on the scale ranged between $(0.31-0.78)$, and that the values of the corrected correlation coefficients for items of the "motor skills" dimension in their dimension ranged from Between (0.44-0.78) and on the scale, it ranged between (0.33-0.76).

Pearson correlation coefficients were calculated for the relationship of the dimensions of adaptive behavior with the scale, and the interconnected Pearson correlation coefficients were calculated for the relationship of dimensions between each other, as shown in Table 4. 
Table 4. Values of Pearson correlation coefficients for the relationship of dimensions of adaptive behavior to the scale and the interconnection of Pearson correlation coefficients of the dimensional relationship between each other

\begin{tabular}{ccccc}
\hline Relationship* & Communication & Daily life skills & Socialization & Motor skills \\
\hline Daily life skills & 0.68 & & & \\
Socialization & 0.71 & 0.81 & & \\
Motor skills & 0.55 & 0.78 & 0.77 & \\
Total scale & 0.78 & 0.95 & 0.93 & 0.88 \\
\hline
\end{tabular}

* Statistically significant at the level of significance $(\alpha=0.05)$.

Table 4 illustrates that the values of the correlation coefficients of the dimensions of the adaptive behavior of the scale ranged between (0.78-0.95), while the values of the dimension correlation coefficients between each other ranged between $(0.55-0.81)$.

\section{Stability of scale}

The adaptive behavior scale was applied to an exploratory sample consisting of twenty children with simple intellectual disability at the Fina Al-Khair Center for Special Education from outside the study sample in a (Test-Retest) method with an interval of two weeks between the two applications. Where the stability coefficients of the internal consistency of the scale and of its dimensions were calculated using the Cronbach's alpha equation (Cronbach's $\alpha$ ), and the repetition stability coefficients for the scale and its dimensions were also calculated using the Pearson correlation coefficient between the first and second applications, as shown in Table 5.

Table 5. The values of the stability coefficients of internal consistency and repetition for the adaptive behavior scale and its dimensions

\begin{tabular}{cccc}
\hline \multirow{2}{*}{ Scale and dimensions } & \multicolumn{2}{c}{ Stability coefficients: } & \multirow{2}{*}{ Items } \\
\cline { 2 - 3 } & Internal consistency & *repetition & \\
\hline communication & 0.83 & 0.89 & 22 \\
Daily life skills & 0.97 & 0.84 & 32 \\
Socialization & 0.95 & 0.87 & 28 \\
Motor skills & 0.93 & 0.91 & 20 \\
Total scale & 0.98 & 0.82 & 102 \\
\hline
\end{tabular}

* Statistically significant at the level of significance $(\alpha=0.05)$.

Table 5 shows that the value of the internal consistency coefficient of the scale reached ( 0.98$)$, and its value for the scale dimensions ranged between (0.83-0.97). It is clear that the value of the repetition stability coefficients for the scale reached (0.82), and its values for the scale dimensions ranged between (0.84-0.91).

Adaptive Behavior Scale Correction for Children with Intellectual Disabilities

The Adaptive Behavior Scale for Children with Simple Intellectual Disability included (102) items in its final form, according to the estimation of the triple Likert scale that includes alternatives: [(Not master) and has one degree; (Attempts) and has two degrees; (The skill is mastered) and has three degrees]. The statistical model with relative ranking was adopted for the purpose of classifying the arithmetic mean of the responses of the study sample individuals on the adaptive behavior scale for children with simple intellectual disability and its related dimensions and the items of the dimensions into three levels of mastery as follows:

\begin{tabular}{ccc}
\hline Level & The category of the arithmetic mean corresponding to it \\
\hline High & 2.34 & 3.00 \\
Moderate & 1.67 & 2.33 \\
Low & 1.00 & 1.66 \\
\hline
\end{tabular}

By calculating the length of the category according to the quotient of dividing the range by number of provisions contemplated in this study. According to the following equation:

Category length $=$ Term $/($ provisions $)=$ Highest ranking - lowest ranking $/$ number of provisions $=3-1 / 3=2 / 3=0.66$ 


\subsection{Study Procedures}

The study followed the following procedures:

1) Portage's Early Intervention Training Program was adopted, and written consent was obtained from the publisher.

2) Content verified for the Portage Early Intervention Training Program.

3) The two study scales were prepared, adaptive behavior among children with simple intellectual disability and cognitive competencies of their mothers.

4) The indications of validity and reliability of the two study scales were verified.

5) One of the specialists, who is the director of the (Fina Al-Khair) center, was trained on the techniques of the Portage program.

6) The pre-application of the cognitive competency scale was conducted by the researcher on mothers of children with intellectual disabilities who were enrolled in the (Fina Al-Khair) Center for Special Education.

7) The treatment was carried out by the researcher explaining the Portage Early Intervention Training Program for mothers of children with intellectual disabilities.

8) The implementation of the training program for mothers took a week, from Saturday to Thursday, with 6 training sessions lasting an hour and a half.

9) Meeting with mothers used to take place every Saturday at the Fina El-Khair Center.

10) Time was enough to repeat the explanation to the mother who was absent from the previous session.

11) After completing the explanation of the training program, the mothers applied what they had learned to a case outside the sample included in the study, in order to ensure the extent of their understanding of the training program.

12) The post-application of the cognitive competency scale of mothers of children with intellectual disabilities was conducted by the researcher.

13) The pre-application of the Adaptive Behavior Scale was performed on the study sample of children with intellectual disability by the specialist at Fina Al-Khair Center for Special Education, and she has been in direct contact with the child for more than 6 months.

14) Mothers evaluated their children using the Portage scale check-list.

15) Mothers identified the strengths and weaknesses of their son, on a sub-dimension of one of the four dimensions included in the study, which are relationships, interaction with others, communication, and independence.

16) The researcher developed a plan directed to the mother (the family services plan), to address the child's weakness; it depends mainly on the implementation of the daily routine for the child.

17) The plan was developed through the list of activities according to the second version of the Portage Early Intervention Program.

18) A WhatsApp group was created for the purposes of communication, answering inquiries, and following up mothers in implementing the goals, and the specialist would contact the mothers by phone if there was a need for that.

19) Meeting with mothers took place every Saturday in the presence of her son,with a slight intellectual disability, in order to ensure that he mastered the planned skill, by implementing it in front of the specialist and the researcher.

20) The transition to the other sub-dimension would take place if the child successfully implemented the skill in front of the specialist and the researcher.

21) Each child was trained on one goal for each skill, with four goals throughout the study period.

22) The post-application of the Adaptive Behavior Scale was performed on children with simple intellectual disabilities who were enrolled in the (Fina Al-Khair) Center for Special Education by the trained specialist who has been in direct contact and acquainted with the child for more than 6 months.

23) The follow up application of the Adaptive Behavior Scale was performed on children with simple intellectual disability one month after the end of the implementation of the Portage Early Intervention Training Program 
by the trained specialist who has been in direct contact with the child for more than 6 months.

\subsection{Study Layout/Study Design}

The one-group design was used with two tests (pre and post) or (post and follow up) that follow the pre-experimental designs, as follows:

$\begin{array}{llll}\mathrm{O}_{1} & \mathrm{X} & \mathrm{O}_{2} & \\ \mathrm{O}_{2} & \mathrm{X} & \mathrm{O}_{2} & \mathrm{O}_{3}\end{array}$

Where:

O1: Pre-test of the two scales, the adaptive behavior for children with simple intellectual disability and the cognitive competency scale of their mothers

\section{$\mathrm{X}$ : Treatment (Portage Early Intervention Training Program, Second Edition)}

O2: Post-test of the two scales, the adaptive behavior for children with simple intellectual disability and cognitive competencies of their mothers

O3: Follow-up test of the Adaptive Behavior Scale for children with intellectual disability.

\section{Results}

The study aimed to reveal the effectiveness of the Portage Early Intervention Program in improving the cognitive competencies of mothers of children with simple intellectual disabilities and developing adaptive behavior skills of their children by answering the following study questions:

First: Results related to the first question: "Are there statistically significant differences at the level of significance $(\alpha=0.05)$ between the arithmetic means of the pre and posttests of the performance of mothers of children with simple intellectual disabilities on the Cognitive Competency Scale?"

To answer the first study question: The two means and the standard deviations of the pre and posttests of the performance of mothers of children with simple intellectual disability were calculated on the Cognitive Competency Scale, then the t-test was used for correlated samples, as shown in Table 6.

Table 6. Results of t-test for correlated samples between pre and post-tests of the performance of mothers of children with simple intellectual disability on the of cognitive competency scale

\begin{tabular}{cccccccc}
\hline Test & Mean & standard deviation & Correlation coefficient & T & F degree & Statistical significance & improvement Percentage \\
\hline Pre & 2.30 & 2.91 & 0.24 & & & & \\
Post & 18.10 & 2.51 & $-14.87^{*}$ & 9 & 0.00 & 83.16 \\
\hline
\end{tabular}

* Statistically significant at the level of significance $(\alpha=0.05)$.

Table 6 shows that there was a statistically significant difference at the level of significance $(\alpha=0.05)$ between the means of the pre and posttests of the performance of mothers of children with simple intellectual disabilities on the cognitive competency scale. In favor of the post-test after receiving the Portage program for early intervention compared to the pre-test of their performance. This is with an improvement of $(83.16 \%)$ for the post-test compared to the pretest. Figure 1 shows the mean of the pre and post-tests and the rates of improvement of the posttest compared to the pre-test of the performance of mothers of children with simple intellectual disabilities on the cognitive competency scale separately.

Second: Results related to the second question: "Are there statistically significant differences at the level of significance $(\alpha=0.05)$ between the arithmetic means of the pre and posttests of the performance of children with simple intellectual disability on the Adaptive Behavior Scale?"

To answer the second study question: The two means and standard deviations of the pre and post-tests of the performance of children with simple intellectual disability were calculated on the adaptive behavior scale and its related dimensions (communication, daily life skills, socialization, motor skills), then a t-test was used for correlated samples. This is illustrated in Table 7. 
Table 7. Results of t-test for correlated samples between pre and post-tests of performance of children with simple intellectual disability on the adaptive behavior scale and its dimensions (communication, daily life skills, socialization, motor skills)

\begin{tabular}{|c|c|c|c|c|c|c|c|c|}
\hline 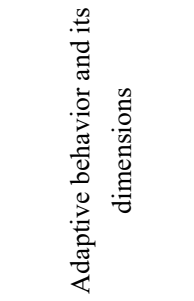 & 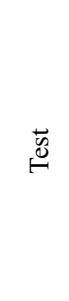 & $\stackrel{\mathbb{E}}{\Sigma}^{\tilde{E}}$ & 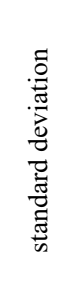 & 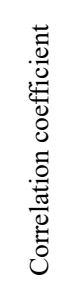 & $*_{+}$ & 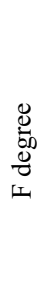 & 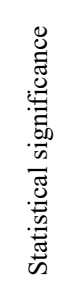 & 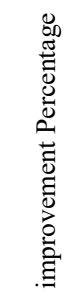 \\
\hline \multirow{2}{*}{ Communication } & Pre & 1.53 & 0.32 & \multirow{2}{*}{0.86} & & & & \\
\hline & Post & 1.99 & 0.30 & & -8.84 & 9 & 0.00 & 15.33 \\
\hline \multirow{2}{*}{ Daily life skills } & Pre & 1.82 & 0.47 & \multirow{2}{*}{0.94} & & & & \\
\hline & Post & 2.33 & 0.30 & & -7.74 & 9 & 0.00 & 17.00 \\
\hline \multirow{2}{*}{ Socialization } & Pre & 1.83 & 0.40 & \multirow{2}{*}{0.92} & & & & \\
\hline & Post & 2.27 & 0.35 & & -8.54 & 9 & 0.00 & 14.66 \\
\hline \multirow{2}{*}{ Motor skills } & Pre & 1.96 & 0.38 & \multirow{2}{*}{0.91} & & & & \\
\hline & Post & 2.37 & 0.27 & & -7.64 & 9 & 0.00 & 13.66 \\
\hline \multirow{2}{*}{ Total scale } & Pre & 1.79 & 0.38 & \multirow{2}{*}{0.95} & & & & \\
\hline & Post & 2.25 & 0.29 & & -10.75 & 9 & 0.00 & 15.33 \\
\hline
\end{tabular}

* Statistically significant at the level of significance $(\alpha=0.05)$.

Table 7 illustrates the presence of a statistically significant difference at the level of significance $(\alpha=0.05)$ between the two means of the pre and posttests of the performance of children with simple intellectual disability on the adaptive behavior scale and its related dimensions (communication, daily life skills, socialization, motor skills). In favor of the post-test of the performance of children with simple intellectual disability on the adaptive behavior scale and its related dimensions (communication, daily life skills, socialization, motor skills) after receiving the Portage program for early intervention compared to the pre-test of their performance. The improvement rates for the post-test compared to the pre-test were $(15.33 \%$ for total, $15.33 \%$ for communication, $17 \%$ for daily life skills, $14.66 \%$ for socialization, and $13.66 \%$ for motor skills).

Third: The results related to the third question: "Are there statistically significant differences at the level of significance $(\alpha=0.05)$ between the arithmetic means of the post and follow up tests of the performance of children with intellectual disabilities on the Adaptive Behavior Scale?"

To answer the third study question: The two means and standard deviations of the post and follow up tests of the performance of children with simple intellectual disability were calculated on the adaptive behavior scale and its dimensions (communication, daily life skills, socialization, motor skills), then a t-test was used for correlated samples. This is as illustrated in Table 8. 
Table 8 . The performance of children in pre and post- test on adaptive behavior skills

\begin{tabular}{|c|c|c|c|c|c|c|}
\hline No. & Application & Communication & Daily life skills & Socialization & Motor skills & Adaptive behavior in children with intellectual disability \\
\hline \multirow{2}{*}{1} & Pre & 1.27 & 1.38 & 1.57 & 1.85 & 1.5 \\
\hline & Post & 1.73 & 2.13 & 2 & 2.05 & 1.99 \\
\hline \multirow{2}{*}{2} & Pre & 1.41 & 1.31 & 1.57 & 1.9 & 1.52 \\
\hline & Post & 2.18 & 2.09 & 2.14 & 2.3 & 2.17 \\
\hline \multirow{2}{*}{3} & Pre & 1.73 & 2.38 & 2.32 & 2.2 & 2.19 \\
\hline & Post & 2.23 & 2.56 & 2.68 & 2.65 & 2.54 \\
\hline \multirow{2}{*}{4} & Pre & 1.45 & 1.84 & 1.75 & 2.05 & 1.77 \\
\hline & Post & 2.05 & 2.31 & 2.32 & 2.55 & 2.3 \\
\hline \multirow{2}{*}{5} & Pre & 1.59 & 2.22 & 1.64 & 1.75 & 1.83 \\
\hline & Post & 2.05 & 2.66 & 2.29 & 2.25 & 2.34 \\
\hline \multirow{2}{*}{6} & Pre & 1.23 & 1.38 & 1.39 & 1.85 & 1.44 \\
\hline & Post & 1.73 & 1.91 & 1.61 & 2.25 & 1.85 \\
\hline \multirow{2}{*}{7} & Pre & 1.73 & 2.09 & 2.14 & 2.3 & 2.07 \\
\hline & Post & 2.18 & 2.66 & 2.57 & 2.6 & 2.52 \\
\hline \multirow{2}{*}{8} & Pre & 1.23 & 1.28 & 1.46 & 1.35 & 1.33 \\
\hline & Post & 1.68 & 2.06 & 2 & 2.1 & 1.97 \\
\hline \multirow{2}{*}{9} & Pre & 1.36 & 1.78 & 1.86 & 1.6 & 1.68 \\
\hline & Post & 1.55 & 2.19 & 2.29 & 2.1 & 2.06 \\
\hline \multirow{2}{*}{10} & Pre & 2.27 & 2.5 & 2.61 & 2.7 & 2.52 \\
\hline & Post & 2.5 & 2.75 & 2.75 & 2.85 & 2.72 \\
\hline \multirow{2}{*}{ Total- } & Pre & 1.527 & 1.816 & 1.831 & 1.955 & 1.785 \\
\hline & Post & 1.988 & 2.332 & 2.265 & 2.37 & 2.246 \\
\hline
\end{tabular}

Table 9. Results of the t-test for correlated samples between the post and follow up tests of the performance of children with simple intellectual disability on the adaptive behavior scale and its dimensions (communication, daily life skills, socialization, motor skills)

\begin{tabular}{|c|c|c|c|c|c|c|c|c|}
\hline 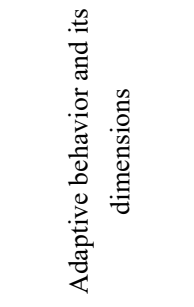 & 岂 & $\sum^{\text {ฮँ }}$ & 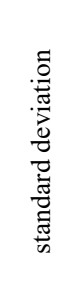 & 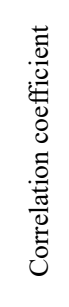 & ${ }_{+}^{*}$ & 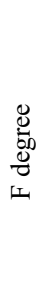 & 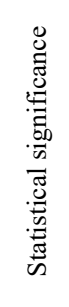 & 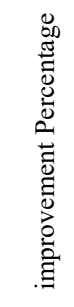 \\
\hline \multirow{2}{*}{ Communication } & Post & 1.99 & 0.30 & \multirow{2}{*}{0.78} & & & & \\
\hline & Follow up & 2.34 & 0.33 & & -5.30 & 9 & 0.00 & 11.66 \\
\hline \multirow{2}{*}{ Daily life skills } & Post & 2.33 & 0.30 & \multirow{2}{*}{0.86} & & & & \\
\hline & Follow up & 2.58 & 0.33 & & -4.82 & 9 & 0.00 & 8.33 \\
\hline \multirow{2}{*}{ Socialization } & Post & 2.27 & 0.35 & \multirow{2}{*}{0.88} & & & & \\
\hline & Follow up & 2.63 & 0.38 & & -6.48 & 9 & 0.00 & 12.00 \\
\hline \multirow{2}{*}{ Motor skills } & Post & 2.37 & 0.35 & \multirow{2}{*}{0.73} & & & & \\
\hline & Follow up & 2.64 & 0.28 & & -4.87 & 9 & 0.00 & 12.33 \\
\hline \multirow{2}{*}{ Total scale } & Post & 2.25 & 0.29 & \multirow{2}{*}{0.90} & & & & \\
\hline & Follow up & 2.55 & 0.30 & & -7.36 & 9 & 0.00 & 10.00 \\
\hline
\end{tabular}

* Statistically significant at the level of significance $(\alpha=0.05)$.

Table 9 illustrates the presence of a statistically significant difference at the level of significance $(\alpha=0.05)$ between the two arithmetic means of the two tests, the post and the follow up, of the performance of children with simple intellectual disability on the adaptive behavior scale and its dimensions (communication, daily life skills, socialization, motor skills), in favor of the follow up test after receiving the Portage program for early intervention 
compared to the post-test of their performance on it. The improvement rates for the follow up test compared to posttest were $(10 \%$ for total, $11.66 \%$ for communication, $8.33 \%$ for daily life skills, $12 \%$ for socialization, and $12.33 \%$ for motor skills).

Table 10. The performance of children in the two tests, post and follow-up, on the skills of adaptive behavior

\begin{tabular}{|c|c|c|c|c|c|c|}
\hline No. & Application & Communication & Daily life skills & Socialization & Motor skills & Adaptive behavior in children with intellectual disability \\
\hline \multirow{2}{*}{1} & Post & 1.73 & 2.13 & 2 & 2.05 & 1.99 \\
\hline & Follow up & 2.05 & 2.28 & 2.25 & 2.35 & 2.24 \\
\hline \multirow{2}{*}{2} & Post & 2.18 & 2.09 & 2.14 & 2.3 & 2.17 \\
\hline & Follow up & 2.18 & 2.22 & 2.46 & 2.6 & 2.35 \\
\hline \multirow{2}{*}{3} & Post & 2.23 & 2.56 & 2.68 & 2.65 & 2.54 \\
\hline & Follow up & 2.64 & 2.81 & 2.96 & 2.95 & 2.84 \\
\hline \multirow{2}{*}{4} & Post & 2.05 & 2.31 & 2.32 & 2.55 & 2.3 \\
\hline & Follow up & 2.55 & 2.75 & 3 & 2.85 & 2.79 \\
\hline \multirow{2}{*}{5} & Post & 2.05 & 2.66 & 2.29 & 2.25 & 2.34 \\
\hline & Follow up & 2.5 & 2.84 & 2.64 & 2.7 & 2.69 \\
\hline \multirow{2}{*}{6} & Post & 1.73 & 1.91 & 1.61 & 2.25 & 1.85 \\
\hline & Follow up & 2.23 & 2.22 & 2.11 & 2.55 & 2.25 \\
\hline \multirow{2}{*}{7} & Post & 2.18 & 2.66 & 2.57 & 2.6 & 2.52 \\
\hline & Follow up & 2.86 & 2.97 & 2.93 & 2.75 & 2.89 \\
\hline \multirow{2}{*}{8} & Post & 1.68 & 2.06 & 2 & 2.1 & 1.97 \\
\hline & Follow up & 2.09 & 2.13 & 2.07 & 2.1 & 2.1 \\
\hline \multirow{2}{*}{9} & Post & 1.55 & 2.19 & 2.29 & 2.1 & 2.06 \\
\hline & Follow up & 1.77 & 2.78 & 2.86 & 2.5 & 2.53 \\
\hline \multirow{2}{*}{10} & Post & 2.5 & 2.75 & 2.75 & 2.85 & 2.72 \\
\hline & Follow up & 2.55 & 2.84 & 3 & 3 & 2.85 \\
\hline \multirow{2}{*}{ Total } & Post & 1.988 & 2.332 & 2.265 & 2.37 & 2.246 \\
\hline & Follow up & 2.342 & 2.584 & 2.628 & 2.635 & 2.553 \\
\hline
\end{tabular}

\section{Discussing}

This chapter discusses the results of the study questions as they appear in the presentation of the results, as follows:

First: Discussing the results related to the question that stated: "Are there statistically significant differences at the level of significance $(\alpha=0.05)$ between the arithmetic mean of the pre and post-tests of the performance of mothers of children with simple intellectual disabilities on the cognitive competency scale?"

The results of the first study question showed a statistically significant difference between the two means of the pre and posttests of the performance of mothers of children with simple intellectual disabilities on the cognitive competency scale, in favor of the post-test, after receiving the Portage Early Intervention program compared to pre-test of their performance. This was observed through the percentage of improvement of the post-test compared to the pre-test. This means that there is a very high impact of the Portage program in improving the cognitive competencies of mothers of children with simple intellectual disabilities. This result can be explained by the fact that the Portage training program is one of the early intervention models that improves cognitive competencies among mothers of children with simple intellectual disabilities. The result can also be explained by the positive impact of the Portage Early Intervention Training Program in terms of its work on enabling mothers to understand the needs of their children. And the program seeks to achieve several goals including: helping the family in raising its children, training them and relieving their burdens, reducing pressure on them, reducing the confusion of the families of children with simple intellectual disabilities, this prevents the formation of unconstructive patterns of upbringing for their children with simple intellectual disabilities.

We also note that the rate of improvement is high among mothers in general, and that some of them have reached an improvement rate of $(100 \%)$ on the cognitive competency scale, the reason for this improvement is that mothers have not previously undergone any of the early intervention programs, as well as their lack of knowledge of the application of the Portage program of early intervention. The researcher also noted that the low rate means that the 
mother has prior knowledge that reduced the rate of improvement.

Mothers' interest in training on the program and showing high motivation towards acquiring skills and competencies to impart them to children was also noted.

This result is consistent with the result of the study of Qasim (2017) regarding the effectiveness of the Portage program for early intervention in improving the cognitive competencies of mothers of children with simple intellectual disability as a result of the training they received. And with the result of the study of Al-Bdour (2017) in terms of improving the cognitive competencies of parents of children with autism spectrum, and in agreement with the result of the study of Biber and Ural (2016) in terms of the existence of a statistically significant difference at the level of significance $(\alpha=0.05)$ between the arithmetic means of the pre and post-tests; in favor of the post-test of the participation of families of children in the age group (4-6) years enrolled in the kindergarten in Balikesir compared to its pre-test; this is due to the effect of the Portage Early Intervention Program.

Second: Discussion of the results related to the question that stated: "Are there statistically significant differences at the level of significance $(\alpha=0.05)$ between the arithmetic mean of the pre and post-tests of the performance of children with simple intellectual disability on the adaptive behavior scale?"

The results of the second study question showed a statistically significant difference at the level of significance ( $\alpha$ $=0.05$ ) between the arithmetic means of the pre and post-tests of the performance of children with simple intellectual disability on the adaptive behavior scale and its dimensions, in favor of the post-tests after receiving the Portage Early Intervention program compared to the pre-test of their performance; in other words, there is a low impact attributable to the Portage program in improving the post-test of adaptive behavior in children with simple intellectual disability. This result can be explained by the fact that the Portage program seeks to achieve several goals including reducing the dependence of children with simple intellectual disability on their families, as well as preventing or reducing the negative effects of disability on the growth and development of the child, helping the child to adapt to the surrounding environment and reducing the child's educational and behavioral problems.

This result is consistent with the result of the Al-Qudah (2010) in terms of having a statistically significant effect between the arithmetic means of the performance of children with Down syndrome on the Vineland scale of social maturity and the skills related to it (self-skills, household activities, environmental skills) according to the group; and in favor of the experimental group compared to the control group, And it agrees with the results of the study of Al shammari (2014) in terms of the presence of a statistically significant difference between the two arithmetic means for the post-test of the performance of Down syndrome children in kindergartens in the State of Kuwait on the two scales of motor skills and self-concept attributed to the group, in favor of the experimental group who received the motor activities in the Portage Early Intervention Program compared to the control group who did not receive any program. And with the result of Ibrahim (2015) study in terms of the existence of a statistically significant difference between the two arithmetic means for the post-test of the performance of kindergarten children (4-6) years in the city of Taif on the scale of technical and innovative skills attributed to the group; in favor of the experimental group members who received some of the Portage program activities compared to the control group members who did not receive the relevant Portage program activities.

And it agrees with the result of Qasim (2017) study in terms of the existence of a statistically significant difference between the two arithmetic means of the pre and post-tests of children's development in the fields (socio-cognitive, linguistic, kinetic, and self-help), in favor of the post-test of children's development in the relevant areas compared to the pre-test. This indicates the efficiency of the home teachers trained in using Portage for the comprehensive development of early childhood. This result is consistent with the result of Heiba (2017) study in terms of the existence of a statistically significant difference between the two arithmetic means of the post-test to improve the psycho-linguistic development of a sample of children with simple intellectual disability in the Republic of Egypt attributable to the group, in favor of the experimental group who received the Portage program compared to the control group who did not receive the program. It also agrees with the results of the study of Biber and Ural (2016) in terms of the existence of a statistically significant difference between the arithmetic means of the pre and post-tests of the development of children in the age group (4-6) years enrolled in kindergarten in Balikesir; in favor of the post-tests of the development of children in the age group (4-6) years enrolled in the kindergarten in Balikesir compared to its pre-test due to the effect of the Portage Early Intervention Program. This result is consistent with the results of the study of Artero Prado et al. (2012) in terms of the existence of a statistically significant difference between the arithmetic means of the pre and post-tests to assess the growth and development of children in kindergarten in Brazil. In favor of post-tests to assess the growth and development of kindergarten children in Brazil compared to pre-test. This is due to the impact of the Early Intervention Program. This result is 
also consistent with the result of the study of Biber and Ural (2016) in terms of the existence of statistically significant differences between the arithmetic means of the pre and post-tests of the performance of children between (5-6) years in child care centers in Izmir-Turkey in aspects of language, personal care and mental and social development. In favor of the post-test in comparison to the pre-test: This is due to the effect of the family intervention program for responsible employees in social affairs and child protection institutions. This result is also consistent with the result of the study of Pianezzola de Oliveira et al. (2018) in terms of the improvement of the post-test of the performance of children with Down syndrome in Brazil on the Child Behavior Growth Scale, compared to the pre-test for them.

Third: Discussion of the results related to the question that stated: "Are there statistically significant differences at the level of significance $(\alpha=0.05)$ between the arithmetic means of the post and follow up tests of the performance of children with simple intellectual disabilities on the adaptive behavior scale?"

The results of the third study question showed that there was a statistically significant difference at the level of significance $(\alpha=0.05)$ between the two arithmetic means of the post and follow up tests of the performance of children with simple intellectual disability on the adaptive behavior scale and its dimensions. In favor of the follow up test (after receiving the Portage program for early intervention compared to the post-test of their performance on it, with improvement rates for the follow up test compared to the post-test. This means having an effect that ranges between (very low and low) Which is attributed to the Portage program in improving the follow up test of adaptive behavior in children with simple intellectual disability. This result can be explained by the fact that the Portage Early Intervention Training Program operates in two domains: a short-term and has a cognitive nature, and a long-term, and it has a skills-based nature that depends on analysis, synthesis and evaluation, but of course, with modest percentages compared to normal children, due to the presence of mental disability despite its simplicity.

This result differs with the result of Al-Ataiwi (2014) study, in terms of children not retaining these skills in follow up test. It even exceeded it by a statistically significant difference at the level of significance $(\alpha=0.05)$.

\section{Conclusion}

This study ended with a set of research and educational recommendations, Study the effectiveness of the Portage early intervention training program on other skills not included in this study, Study the extent to which mothers benefit from early intervention programs and help them in dealing with their children.

\section{References}

Abd Alaziz, O. (2012). The needs of the families of children with mental disabilities and their relationship to gender, age and degree of disability for the mentally handicapped. The International Journal of Specialized Education, 1(11).

Al Rousan, F. (2018). Intelligence and adaptive behavior. Riyadh, Saudi Arabia: Dar Al Zahraa.

Al shammari, H. (2014). The effect of motor activities in the Portage program for early intervention in developing self-concept among children with Down syndrome in the kindergarten stage in the State of Kuwait. Journal of Educational and Psychological Sciences, 15(2), 409-445. https://doi.org/10.12785/jeps/150213

Al-Ali, S. (2010). The effectiveness of the Jordanian image from the Adaptive Behavior Assessment System (ABAS-II) in detecting deficiencies in the adaptive behavior skills of individuals with various disabilities (Unpublished $\mathrm{PhD}$ thesis). The University of Jordan, Jordan.

Al-Bdour, S. (2017). The effectiveness of a training program for parents based on behavioral theory in improving their cognitive competencies and measuring its impact on modifying the behavior of their children with autism in Jordan (Ph.D. University of Islamic Sciences, Jordan).

Al-Otaibi, B. (2004). Psychometric properties of an Arabic image from the Vineland Adaptive Behavior Scale. Arab Journal of Special Education, 7, 8-4.

Al-Qudah, D. (2010). The effectiveness of an early intervention program in developing daily life skills for a group of children with Down syndrome in the age group (3-6) years in Jordan (Unpublished PHD thesis). The University of Jordan, Jordan.

American Psychiatric Association (APA). (2013). Diagnostic and Statistical Manual of Mental Disorders (5th ed. DSM-5). https://doi.org/10.1176/appi.books.9780890425596

Artero Prado, M. T., Fell, R. F., Salmazo, A. S., Claudino Gomes, G. C., Silva, M. S., dos Santos, S. M. T., \& Luiz Fernani, D. C. G. (2012). Evaluation of Children Growth and Development Through the 
Operationalized Portage Inventory. Journal of the Crescimento E Desenvolvimento De Criancas, 4(1), 10-17. https://doi.org/10.5747/cv.2012.v04.n1.v057

Biber, E., \& Ural, O. (2016). The Effect of Early Education Program on Family Involvement and Development of Children at the Age of 5-6. Journal of Theory and Practice in Education, 12(6), 1181-1204.

Ditterline, J., \& Oakland, T. (2009). Relationships Between Adaptive-Behavior and Impairment, In S. Golstein, \& J. Naglieri (Eds.), Assessing Impairment: From Theory To practice (1st ed.). U.S.A: springer. https://doi.org/10.1007/978-1-387-87542-2_4

Duffy, S. (2007). Adaptive Behavior. In W. John, A. James, L. Mulick, \& R. Johnes, (Eds.), Handbook of Intellectual and Developmental Disabilities. USA: Springer.

Hallahan, D., Kaufman, J., \& Pollan, P. (2013). Students with Special Needs: An Introduction to Special Education (Translated by Fathi Jarwan and others). Amman: Dar Al-Fikr, publishers and distributors.

Hamdan, G. (2013). The impact of a parenting program using play on mothers' perceived self-efficacy and the adjustment of their children (Unpublished $\mathrm{PhD}$ thesis). The University of Jordan, Jordan.

Harrison, P., \& Oakland, T. (2003). Adaptive Behavior Assessment System (ABAS-II) (2nd ed.). San Antonio: TX. The Psychological Corporation.

Heiba, H. (2017). The effectiveness of the Portage program in improving the psycho-linguistic development of a sample of mentally handicapped children, who are able to learn. The Journal of Childhood Studies, 20(74), 77-84.

Herwig, J., \& Herman, P. (1993). Portage Multi-State Outreach Project. Final Report.

Ibrahim, H. (2015). The effectiveness of the Portage program in developing some technical and innovative skills for kindergarten children. The Journal of Childhood Studies, 18(66), 1-7.

Janzen, J. (2003). Understanding the Nature of Autism: A guide to the Autism Spectrum Disorders (2nd ed.). USA: the Psychological Corporation.

Pianezzola de Oliveira, R., Azambuja Ilha, D., Mugnol, C. M., Gonçalves Conceição, R. T., Bitencourt, S., da Silva Machado, V., ... \& Skilhan de Almeida, C. (2018). Effect of early intervention in an interdisciplinary group of children with Down syndrome in a special integration center. Fisioterapia Brasil, 19(5), 651-659. https://doi.org/10.33233/fb.v19i5.2711

Qasim, A. (2017). The effectiveness of a training program for early intervention using the Portage program for a sample of graduate students in preparing the home teacher for the comprehensive development of early childhood. Journal of the College of Education, 32(4), 38-80.

Tabbal, S. (2014). Portage Early Learning Program. Amman-Jordan: Debono Center for Teaching Thinking.

\section{Copyrights}

Copyright for this article is retained by the author(s), with first publication rights granted to the journal.

This is an open-access article distributed under the terms and conditions of the Creative Commons Attribution license (http://creativecommons.org/licenses/by/4.0/). 